1978. He reasoned that crucial bits of information about subatomic particles cannot be carried by photons, so other types of particles such as electrons or quarks would also be needed. But there are not enough of these other particles in the radiation to embody all the information, because most of the heat energy from a black hole is in the form of photons. The conundrum became known as the information paradox. It may seem like theoretical nit-picking, but the paradox goes to the very heart of physical theory and its description of reality.

The momentous conclusion that a black hole swallows and permanently obliterates physical information didn't bother Hawking, whose background was in gravitational theory and space-time geometry rather than particle and quantum physics. With theorist Roger Penrose of the University of Oxford, UK, he proved that space and time could have boundaries or edges, called singularities, at which information might enter or leave the Universe. The general theory of relativity predicts that such a singularity lurks at the centre of a black hole, where the gravitational field and space-time warp become infinite. As a consequence, the imploding star's information might disappear from space and time through the hole's singularity. Hawking was sufficiently confident to place a bet with theoretical physicist John Preskill at the California Institute of Technology in Pasadena.

An uncertainty in Hawking's argument was the fate of the singularity. If the black hole evaporated completely then the singularity must presumably disappear too, but the details depend on an incomplete field of physics known as quantum gravity. In recent years, work in string theory - to which Susskind has made seminal contributions - has placed quantum gravity on a more secure foundation. Armed with such arguments, Susskind and others gathered support for the position that information is conserved, against Hawking's claim. In 2004, Hawking called a press conference and announced to the world that he had changed his mind. Black holes did not, after all, irreversibly annihilate information, he said. The bet with Preskill was duly settled in the form, appropriately enough, of an encyclopaedia.
The Black Hole War charts the ups and downs of this lengthy yet good-natured dispute. Susskind skilfully explains the subtleties of the physics that underlie the issue, and includes anecdotes to enliven the technical details. He has stuck to his guns for many years, but nevertheless resists the temptation to gloat over Hawking's eventual capitulation.

Is the matter laid to rest? I don't think so. Hawking justified his reversal by sketching out a calculation, but quantum gravity is still too unrefined for a rigorous proof. The weak point is that, in quantum gravity, the singularity can be replaced by a space-time region with a complicated and changing topology, allowing information to shift from one region of space- time into another disconnected one, perhaps from our Universe to a newly born 'baby universe'. Susskind dismisses this possibility, but the matter is far from resolved. It may be that if we consider the entire 'meta-verse' of all spatial regions, information is never lost. But if we restrict attention to a single universe, or connected region of space, then information can in fact leak out. Deciding the matter is a task for a future generation of theoretical physicists.

Paul Davies is director of the Beyond Center for Fundamental Concepts in Science at Arizona State University, Tempe, Arizona 85287-6505, USA. His latest book is The Goldilocks Enigma: Why Is the Universe Just Right for Life? e-mail:paul.davies@asu.edu

\title{
Maths and mad hatters
}

\section{Lewis Carroll in Numberland: His Fantastical Mathematical Logical Life by Robin Wilson \\ Allen Lane/Norton: 2008. 237 pp/208 pp. $€ 16.99 / \$ 24.95$}

Legend has it that Queen Victoria was so enchanted by Alice's Adventures in Wonderland that she insisted on Lewis Carroll's next work being sent to her. One can imagine her expression as she opened the book that arrived, entitled An Elementary Treatise on Determinants.

Charles Lutwidge Dodgson had many careers. He is best remembered for the sublime nonsense verse he wrote under the name Lewis Carroll. He was a pioneering childrens' photographer and a lay clergyman admired for his sermons. Before all else he was a mathematician who taught generations of students at the University of Oxford, UK, contributed to the fields of geometry, algebra and logic, and used games and puzzles to entertain and instruct. In Lewis Carroll in Numberland, mathematician Robin Wilson reveals Dodgson to be the grandfather of recreational mathematics.

He was precocious, orthodox and craved variety. Born in 1832 in Cheshire, UK, Dodgson was a lecturer at Oxford by his early twenties. At a time when non-Euclidean geometries were catching on, he wrote a four-act play stubbornly arguing that Euclid should remain at the centre of the Oxford curriculum. He invented a method to find the determinants of large matrices, but his strange notation meant that it never caught on. Later, he sought mathematical remedies for real injustices, suggesting tie-break methods for parliamentary elections to his friend Lord Salisbury, and devising a way to make lawn tennis tournaments fairer to the runners-up.

Some work was ahead of its time, especially his efforts to bring mathematics to young people. Although pupils complained of his "singularly dry and perfunctory manner" in the classroom, Dodgson's gift for teaching shone through in dozens of self-published guides for students, and in his letters to children. Wilson shows that he found humour in the plainest of subjects and did not underestimate his young correspondents, once commenting that intelligence seemed to vary inversely with size. In person, he drew their attention using guessing games and feats of memory. He could recite the first 71 digits of pi using a series of nonsense couplets as memory aids, and once contrived
Faust in Copenhagen: A Struggle for the Soul of Physics and the Birth of the Nuclear Age by Gino Segrè (Pimlico, E12.99)

Segrè relays the 1932 gathering of seven leading physicists that "symbolized the end of the political neutrality of physics and physicists, coinciding as it did with the arrival of Hitler and crucial discoveries in nuclear physics that would make possible the subsequent development of the atomic bomb", wrote Finn Aaserud (Nature 448, 869-870; 2007).

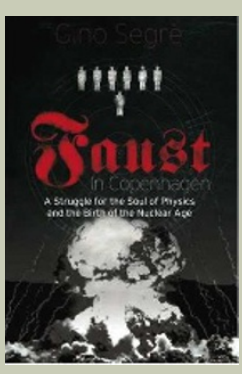

The Annotated Flatland: A Romance of Many Dimensions

by Edwin A. Abbott. Introduction and notes by lan Stewart (Perseus, \$17.95, £10.99)

Abbott's satirical tale of A. Square's journey to The Land of Three Dimensions is annotated by mathematician lan Stewart, providing helpful background on this maths fantasy. Abbott's ideas were thought radical by the Victorians but are now commonplace in both science and science fiction.

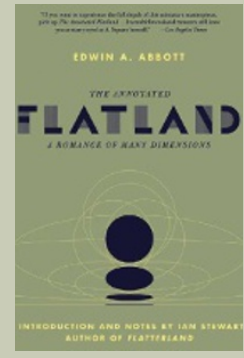




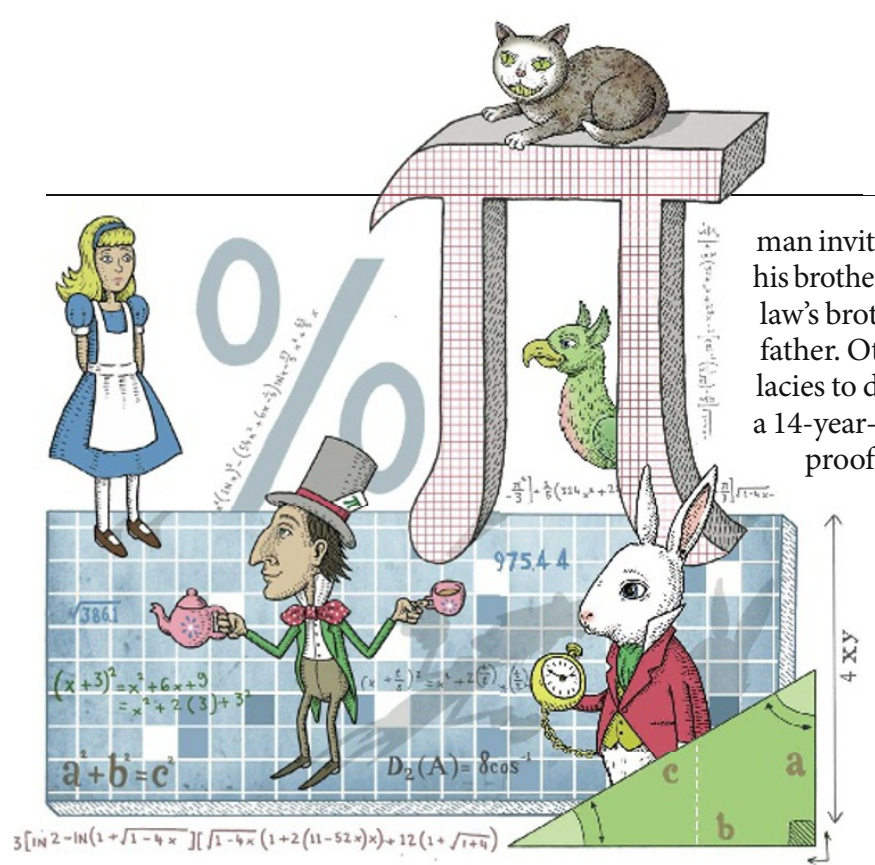

an algorithm that could give the date of every Easter Sunday until 2499.

Sooner or later every child who knew Dodgson would receive a brain teaser. Published in collections with titles such as A Tangled Tale and Pillow Problems Thought Out During Sleepless Nights, many of these word problems required the dutiful application of algebra, trigonometry or geometry. Some needed mere patience and common sense. One devious puzzle asked how many guests would come to a dinner party if a enn. In Dodgson's Game of Logic, published under his pen name to gain a wider audience, one can see some of the punctilious lunacy of the Mad Hatter. Following chains of inference he called 'sillygisms', he led readers from reasonable premises to conclusions such as "Babies cannot manage crocodiles", "No banker fails to shun hyaenas" and "No bird in this aviary lives on mince-pies". These examples are perhaps less interesting as logic than as the stirrings of a systematic kind of literature, also apparent in his symmetrical poem that can be read vertically and horizontally.

Lewis Carroll in Numberland is not a conventional biography. Robin Wilson has winnowed Dodgson's prodigious output into a first-rate scrapbook of proofs and puzzles. Sadly, his tone is often fawning and flat - not up to the standard of mathematical storytelling he set in his previous book, Four Colours Suffice (Allen Lane, 2002), on the history of the conjecture that four colours can fill any map without any bordering countries sharing a colour. By immersing us in Dodgson's correspondence, however, Wilson conjures the spirit of a man who delighted in paradox yet insisted on precision, who held fiercely to the ancients while straining to understand the world around him, and who wanted most of all to stump everyone he knew. Writing for work or pleasure, for children or adults, Wilson shows that Dodgson turned the most sober of problems into child's play.

"Some perhaps may blame me for mixing together things grave and gay," he wrote as Lewis Carroll in an insert to his nonsense poem The Hunting of the Snark. But, he continued, "I do not believe God means us thus to divide life into two halves."

Jascha Hoffman is a writer based in New York. e-mail: jascha@jaschahoffman.com

\section{The creationist controversy}

\author{
Only a Theory: Evolution and the Battle \\ for America's Soul \\ by Kenneth R. Miller \\ Viking: 2008. 256 pp. $\$ 25.95$
}

The United States has a big problem: although we maintain a strong scientific establishment, competitive with the rest of the world in many fields, we also have some of the most backwards proponents of superstitious nonsense in both our electorate and at the highest levels of politics. It is an embarrassment to host laboratories that are at the forefront of scientific research in the same country where presidential candidates are discussing whether Earth is really 6,000 years old as some Bible scholars say, or whether they believe in evolution.

Science and evolution have an advocate in Kenneth Miller, one of North America's eminent knights-errant, a scientist who is active in defending evolutionary theory in the conflict between evolution and creationism. He has been at the centre of many recent debates about science education, most prominently testifying against intelligent design creationism in Pennsylvania's Dover trial, which decided that intelligent design was a religious concept that should not be taught in public schools. He is also a popular speaker, offering the public a grass-roots defence of good science education. Miller's new book Only a Theory is a tour of creationist misconceptions about evolution, such as the one referred to in the book's subtitle - a creationist predicted an inevitable victory in the Dover trial because evolution is "only a theory". The book is also a celebration of the power of evolutionary theory to explain our existence.

Miller is a fine writer who sharply addresses the details of the arguments about intelligent design creationism. When tackling old chestnuts such as the "only a theory" complaint, or Michael Behe's argument for a maximum limit for the number of genetic mutations, or William Dembski's rehash of William Paley's
Riddled with Life: Friendly Worms, Ladybug Sex, and the Parasites That Make Us Who We Are

by Marlene Zuk

(Harvest, \$14, £8.99)

An evolutionary biologist enthusiastically argues that parasites are a driving force behind evolution and that their effects still mould us today. Parasites have shaped us physically and culturally, and affect our minds on a daily basis.

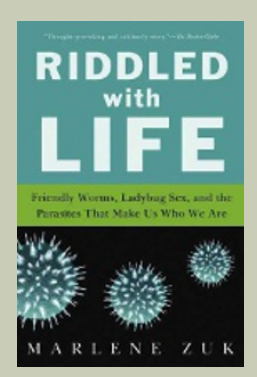

Undermining Science: Suppression and Distortion in the Bush Administration by Seth Shulman

(Univ. California Press, $\$ 16.95$, E9.95)

Shulman explores how US politicians and scientists have misrepresented science to push their own agendas. "A concise, straightforward case history of the politicization of science, ideal for courses on the history, philosophy, sociology and ethics of science," wrote John Horgan (Nature 445, 365-366; 2007).

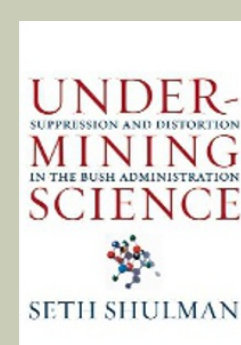

